\title{
La hispanidad periférica en las antípodas \\ el filipino T. H. Pardo de Tavera en la Argentina del Centenario
}

\section{Axel Gasquet}

Université Blaise Pascal, Clermont-Ferrand

\section{Resumen}

Trinidad Hermenegildo Pardo de Tavera (1857-1925) es uno de los más destacados intelectuales de la primera generación de independentistas filipinos, aquella de José Rizal. Visita la Argentina hacia 1914, poco después de los festejos del Centenario de la independencia (1910). El motivo de este viaje fue familiar: su hermano menor, el escultor Félix Pardo de Tavera (1859-1935), habíase afincado en Buenos Aires en 1885. Entre la numerosa obra publicada por Trinidad H. Pardo de Tavera se halla la extensa crónica "Recuerdo de Argentina", editado por The Philippine Review en 1916. El análisis de este testimonio es excepcional, pues los textos de viaje de intelectuales filipinos por Hispanoamérica son muy ocasionales y raros.

El estudio de estas 'memorias argentinas' nos permitirá observar el modelo hispánico de modernidad y civilización ejemplar que el viajero encuentra en Buenos Aires y la Argentina, y, a su vez, la emergencia en su discurso de una comparación y proyección evidente con la situación filipina. La identificación con el modelo de nación triunfante de la Argentina, cosmopolita y abierta a la inmigración europea y mundial, es uno de los puntos mayores que el viajero señala como falencia en el caso filipino. Pardo de Tavera se identifica con el visionario accionar de la élite patricia argentina, cuyo rol director propone, en forma subyacente, imitar por la élite hispano-filipina en tiempos en que su país 
se hallaba bajo administración estadounidense. Sin embargo, su observación de la situación argentina se basa en numerosas lagunas históricas, sociales y políticas, que detallaremos en la conclusión.

\section{Abstract}

Trinidad Hermenegildo Pardo de Tavera (1857-1925) is one of the most relevant intellectuals of the first generation of fighters for Filipino independence. From a prominent Spanish-Filipino family, he lived in Paris for many years before returning to Manila and becoming a public figure. He visited Argentina around 1914 shortly after the Centennial celebrations of independence (1910). In addition to his intellectul curiosity, the reason for this trip was familiar: his younger brother, the sculptor Félix Pardo de Tavera (1859-1935), had settled in Buenos Aires in 1885.

Among the numerous works published by Trinidad Pardo de Tavera is the extensive chronicle Recuerdo de Argentina, published by The Philippine Review in 1916. The analysis of this testimony is exceptional since the travel writings of Filipino intellectuals in Spanish America are very occasional and rare. When Pardo de Tavera visited Argentina, he was already a recognized intellectual in his country, having published numerous original studies on Philippine culture, linguistics, ethnography and history (Santos Cristóbal 7-10). In the last years of his life, between 1922 and 1925, Trinidad Pardo de Tavera will became director of the National Library and the National Museum.

Pardo de Tavera's perception of Centennial Argentina is nuanced with respect to other well-known testimonies of the official celebrations of the Centenary, in which French President Georges Clemenceau and Infanta Isabel de Borbón (aunt of King Alfonso XIII) had participated together with leaders and distinguished delegations of South American republics and the world. ${ }^{1}$

In this context of exaltation and celebratory solemnity, the testimonies made by Pardo de Tavera are more contrasted than those of other personalities because, at the same time, he did not hide his admiration for the young nation that knew how to get ahead on the path of modern civilization (Argentina projected a triumphant image of national emancipation). The Filipino doctor and intellectual also made some critical observations about the prevailing social 
and political conditions-which the traveler often compares with those of his own country. Positive and negative aspects are assembled equally in their exposure with the predominance of the former. In short, the gaze of Pardo de Tavera is not always condescending with the official discourses of the material, social, educational, institutional and moral progress of the South American republic. Even when it exacerbates the authentic achievements of Argentina, it does so by neglecting those aspects that turn out to be, for him, an ideal "estimable" for the Philippines (immigration, cosmopolitanism, resolute integration to the world economy).

A double question guides our exposition: In what proportion is Pardo de Tavera convinced by the official account of a triumphant Argentine modernity spread by the ruling elite that had run the country for fifty years? To what extent was the Filipino intellectual able to observe the political and social reality of the country outside of the official accounts? Along with the institutional achievements, the integration of the masses of immigrants and material progress, the Argentine State started an ideological self-invention discourse in 1862 designated by Nicolas Shumway as 'guiding fictions'. Adapting the concept to the Argentine case, the historian defines the national fictions in these terms: "The guiding fictions of nations cannot be proven, and indeed are often fabrications as artificial as literary fictions. Yet they are necessary to give individuals a sense of nation, peoplehood, collective identity, and national purpose" (xi). Assuming this, there is one final question: to what extent Pardo de Tavera is eager to extrapolate the material achievements and the Argentine 'guiding fictions' for his own country in search of a modernity capable of satisfying the project of national emancipation?

Written after his visit, his memories do not have a structured internal organization and they break down some of the topics that the author judges "may interest the Filipino reader, of what is seen in Buenos Aires and that touches the economic and political life of the Argentine Republic", notes in which "I have pointed out only those things and facts that without looking have seen and known" (42).

We imagine, although there is never an explicit mention of this, that these impressions are to a certain extent assessed by the experience of almost thirty 
years of life in the country of his brother Felix which coincide with the years in which the country consolidates as a nation modern and dynamic liberal. Despite Trinidad's reservations, it is evident that in order to write his essay, the author also had some important documents on the country, pertaining to economic aspects and international politics.

We will articulate our analytical exposition in three fundamental aspects that regroup the totality of the 46 points approached by the Filipino traveler: a) the miscellaneous personal impressions on the social life; b) the observations on the political, social and economic structure of the country, and c) the future perspectives (or predictions) based on these same observations. In the conclusion we will point out the substantial inadequacies of the testimony carried out by Pardo de Tavera focusing on his historical, social and political shortcomings. For if the overall balance of his impressions is positive, it is extremely uncritical and superficial in other aspects. In effect, Pardo de Tavera does not have a complex and dialectical vision about the current modernity in Argentina. Although it emphasizes contradictory aspects, it wass unable to observe that the process of inclusion of the masses of immigrants-otherwise contrasted and conflictive (Bertoni 121-159)-has its counterpart in the social and political exclusion of the native peoples. In short, Argentina's national wealth results from the direct and violent appropriation of indigenous lands by the national State -to the great benefit of the landed oligarchy, that is, the liberal political elite in power (Gaignard 205-218, 223-282) and the exclusion of the same indigenous peoples from citizenship (Hernández; Sabato 11-29; Viñas).

\section{Keywords}

Argentine State, Centennial Argentina, Guiding Fictions, Modernity in Argentina, Trinidad Hermenegildo Pardo de Tavera 


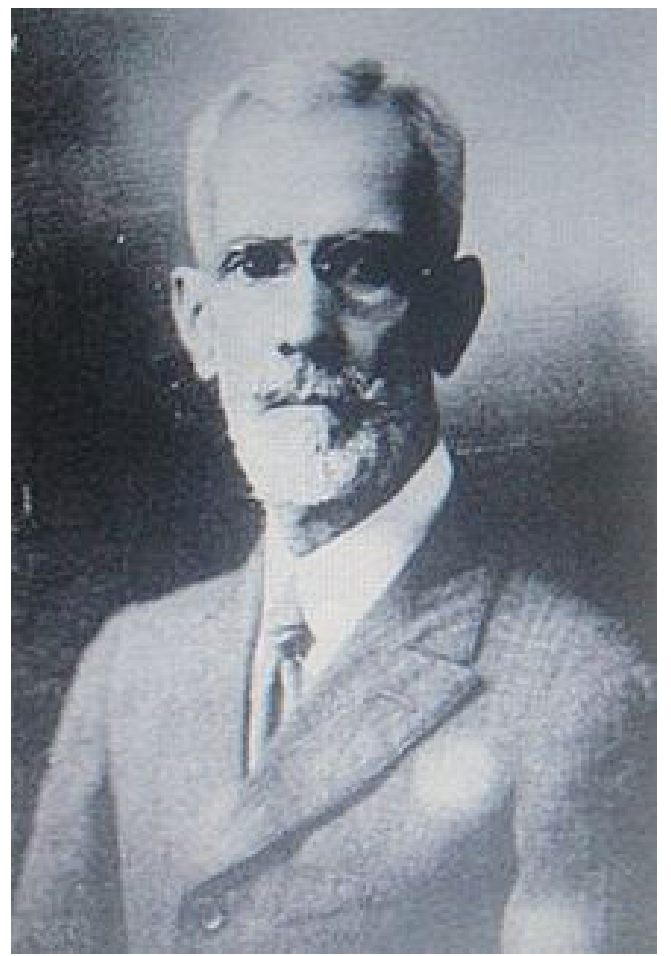

Fig. 1. T. H. Pardo de Tavera, escritor, historiador y político filipino (Taken from Wikimedia Commons). 
Trinidad Hermenegildo Pardo de Tavera (1857-1925) es uno de los más destacados intelectuales de la primera generación de independentistas filipinos, aquella de José Rizal. De encumbrada familia hispano-filipina, vive muchos años en París antes de regresar a Manila y convertirse en una figura pública. Visita la Argentina hacia 1914², poco después de los festejos del Centenario de la independencia $(1910)^{3}$. Amén de su curiosidad, el motivo de este viaje fue familiar: su hermano menor, el escultor Félix Pardo de Tavera (1859-1935), habíase afincado en Buenos Aires en 1885 y forma familia.

Entre la numerosa obra publicada por Trinidad H. Pardo de Tavera se halla la extensa crónica "Recuerdo de Argentina", editado por The Philippine Review en $1916^{4}$. El análisis de este testimonio es excepcional, pues los textos de viaje de intelectuales filipinos por Hispanoamérica son muy ocasionales y raros. Cuando Trinidad H. Pardo de Tavera visita la Argentina ya era un intelectual reconocido en su país, habiendo publicado numerosos eruditos estudios originales sobre la cultura, la lingüística, la etnografía y la historia filipinas (Santos Cristóbal 7-10)5. En los últimos años de su vida, entre 1922 y 1925, Trinidad H. Pardo de Tavera será sucesivamente director de la Biblioteca Nacional y del Museo Nacional.

La percepción de Pardo de Tavera sobre la Argentina del Centenario es matizada respecto a otros conocidos testimonios de los festejos oficiales del Centenario, en los que habían participado el presidente francés Georges Clemenceau y la Infanta Isabel de Borbón (tía del rey Alfonso XIII), junto a mandatarios y distinguidas delegaciones de repúblicas sudamericanas y del mundo. Numerosos artistas y científicos extranjeros también habían estado presentes en las celebraciones y dejaron sus impresiones ${ }^{6}$.

Las celebraciones oficiales estuvieron sin embargo empañadas por los sabotajes y ataques anarquistas, que motivaron el estado de sitio durante varias semanas. El Estado federal argentino y el ayuntamiento de Buenos Aires multiplicaron en aquellos años destacadas inauguraciones urbanísticas, edilicias y paisajísticas monumentales: la flamante escena lírica del Teatro Colón, el Palacio del Congreso, el Parque Centenario, el Palacio de Tribunales, el Parque Tres de Febrero (Palermo), la Avenida de Mayo, además de numerosas tiendas de lujo y edificaciones espectaculares como 
hoteles, fuentes, esculturas y baños, estadios y exposiciones de agricultura e industria, etc.

En dicho contexto de exaltación y solemnidad celebratoria, los testimonios realizados por Pardo de Tavera son más contrastados que los de otras personalidades pues, al mismo tiempo que no oculta su admiración hacia la joven nación que supo adelantarse en el camino de la civilización moderna (la Argentina proyectaba una imagen triunfante de la emancipación nacional), el médico e intelectual filipino también formula algunas observaciones críticas sobre las condiciones sociales y políticas imperantes - que el viajero coteja a menudo con las de su propio país-. Aspectos positivos y negativos se ensamblan por igual en su exposición, con predominio de las primeros. En síntesis, la mirada de Pardo de Tavera no es siempre condescendiente con el discurso oficial del progreso material, social, educativo, institucional y moral de la república sudamericana. Incluso cuando exacerba los logros fehacientes de la Argentina, lo hace soslayando aquellos aspectos que resultan ser, para él, un ideal "estimable" para las Filipinas (inmigración, cosmopolitismo, resuelta integración a la economía mundial).

Un doble interrogante guía nuestra exposición: ¿en qué proporción Pardo de Tavera se muestra convencido por el relato oficial de una modernidad argentina triunfante difundido por la élite gobernante que dirigía el país desde hacía cincuenta años? ¿En qué medida el intelectual filipino estaba en medida de observar la realidad política y social del país por fuera del relato oficial? Junto a las realizaciones institucionales, la integración de las masas de inmigrantes y los progresos materiales, el Estado argentino puso en marcha desde 1862 un discurso ideológico de auto-invención, designado por Nicolas Shumway como guiding fictions. Adaptando el concepto al caso argentino, el historiador define las ficciones nacionales en estos términos: "The guiding fictions of nations cannot be proven, and indeed are often fabrications as artificial as literary fictions. Yet they are necessary to give individuals a sense of nation, peoplehood, collective identity, and national purpose" (xi). Asumiendo esto, cabe un último interrogante: ¿en qué medida Pardo de Tavera ansía extrapolar las realizaciones materiales y las "guiding 
fictions" argentinas para su propio país en busca de una modernidad capaz de satisfacer el proyecto de emancipación nacional?

El viaje de Trinidad Pardo de Tavera se vio interrumpido de forma abrupta por asuntos que reclamaban su presencia en París. Le escribe al director de The Philippine Review:

Yo quería haberme quedado algún tiempo más, pero un suceso inesperado me hizo volver a Europa antes de lo que yo me proponía, y no sólo me vine cuando no lo calculé, sino que dejé, por un lado y por otro, libros y papeles que, si los tuviera ahora, me servirían para dar a Vd. datos más circunstanciados y más preciosos. $(42)^{7}$

Redactados con posterioridad a su visita, sus recuerdos no tienen una organización interna estructurada y desgranan en 46 puntos algunos de los temas que el autor juzga "puede(n) interesar al lector filipino, de aquello que se ve en Buenos Aires y que toca a la vida económica y política de la República Argentina", notas en las que "he apuntado sólo aquellas cosas y hechos que sin buscar he visto y sabido" (42). Imaginamos, aunque nunca se haga mención explícita a esto, que estas impresiones están en cierta medida aquilatadas por la experiencia de casi treinta años de vida en el país de su hermano Félix, que coinciden con los años en que el país se consolida como una nación liberal moderna y dinámica. Pese a los reparos de Trinidad, es evidente que para redactar su ensayo el autor dispuso también de algunos documentos destacados sobre el país, en aspectos económicos y de política internacional.

Articularemos nuestra exposición analítica en tres aspectos fundamentales que reagrupan la totalidad de los 46 puntos abordados por el viajero filipino: a) las misceláneas impresiones personales sobre la vida social, b) las observaciones sobre la estructura política, social y económica del país, y c) las perspectivas futuras (o vaticinios) sustentadas en estas mismas observaciones. En la conclusión señalaremos las insuficiencias sustanciales del testimonio realizado por Pardo de Tavera, centrándonos en sus falencias históricas, sociales y políticas. Pues si el balance global de sus impresiones es positivo, resulta sumamente acrítico y superficial en otros aspectos. En 
efecto, Pardo de Tavera no tiene una visión compleja y dialéctica sobre la modernidad en curso en la Argentina; aunque subraya aspectos contradictorios, es incapaz de observar que el proceso de inclusión de las masas de inmigrantes-por demás contrastado y conflictivo (Bertoni 121-159) - tiene su contracara en la exclusión social y política de los pueblos nativos. En fin, de que la riqueza nacional argentina resulta de la apropiación directa y violenta de las tierras indígenas por parte del Estado nacional -para gran beneficio de la oligarquía terrateniente, esto es, la élite política liberal en el poder (Gaignard 205-218, 223-282)-y la exclusión de los pueblos indígenas de la ciudadanía ${ }^{8}$ (Hernández; Sábato 11-29; Viñas).

\section{Improntas de la vida social y la urbanidad}

Buenos Aires es descrita en términos positivos como una ciudad dinámica y moderna, no sólo por su composición social y elevado cosmopolitismo, sino por sus infraestructuras: portuaria y aduana, de transporte, higiénicas (salud, agua corriente), urbanismo, edilicias, vida cultural, vestimenta y moda, etc. Habiendo hecho escalas en Brasil y Uruguay, "al llegar a Buenos Aires parece que hemos vuelto a Europa" en el hemisferio sur; una urbe europea de ultramar esencialmente blanca:

En Río de Janeiro se ven bastantes negros; en Buenos Aires sólo de cuando en cuando se vislumbra alguno. La población es puramente europea, y el elemento indio que pueda existir se ha fundido tanto, ahogado por la enorme mezcla producida por la inmigración blanca, que, si existe, no se distingue en Buenos Aires (43).

La lengua castellana, según el viajero, "ha evolucionado allá siguiendo los caracteres que ostenta el moderno pueblo argentino" (43); posee modismos, acentos, vocabulario y sintaxis provenientes de mil horizontes, que se funden en lo que Pardo de Tavera designa como el "dialecto argentino". Muy diferente de la lengua castiza, el filipino queda seducido por esta expresión idiomática típicamente argentina, cuyos modismos, acentos y sintaxis "desde el primer momento me encantaron” (43). 
El viajero exulta ante la manifestación de la modernidad porteña, de la que se siente hermanado; este sentimiento constituye su punto de partida y es de alto valor simbólico: "me sentía orgulloso de admirar algo que parecía tocarme" (44). Buenos Aires lo retrotrae a Manila por el vínculo de la lengua: "era la lengua común, que me hacía sentirme envanecido de la hermosa ciudad como si fuera mía, que me hacía participar también del orgullo argentino por su magnífica capital, la que viene en seguida después de París en el mundo latino, que ya es algo" (44).

Queda sorprendido por la pronta capacidad de asimilación que tienen los inmigrantes que llegan masivamente al país. Asimilación social que se hace mediante la rápida adopción de la lengua castellana, y asimilación política mediante el acceso automático a la ciudadanía para los hijos de inmigrantes (política que, entonces, era recusada por las naciones europeas). "Hay que ver con qué orgullo se llaman argentinos los hijos de italianos, españoles, ingleses, etc.: todos los que allí nacen, no solamente son ciudadanos de derecho, sino también patriotas de corazón y de hecho” (44). Pardo de Tavera pensaba que este poder de asimilación social era un fenómeno exclusivo a los Estados Unidos. El poder de asimilación es un correlato de la sociedad moderna, mientras que el fenómeno contrario, el mantenimiento de la identidad originaria o defensa del telurismo, es asociado por el filipino al modelo social tradicional de tipo europeo. Asombra que el ilustre viajero no diga nada en sus recuerdos sobre el sistema educativo que facilita la adopción de la lengua castellana a los hijos de inmigrantes, además de su formación cívica como futuros ciudadanos. La cuestión educativa, pieza clave de la asimilación, es un tema completamente ausente de su crónica de viaje. Esto llama la atención pues la educación era un asunto sobre el cual Pardo de Tavera insistía en sus reflexiones sobre su país natal.

Destaca Trinidad Pardo de Tavera la urbanidad de los modales públicos, tanto de los individuos como de los policías o agentes oficiales. "No se fuma ni escupe en los tranvías, está prohibido, y a nadie se le ocurre desobedecer estas prescripciones" (44). Los policías son serviciales y disciplinados, saben contener sus impulsos y mantienen la sangre fría. Elogia a estos agentes del orden público al punto de considerarlos auténticos modelos: "seguramente 
que los agentes de policía de muchas capitales y grandes ciudades europeas podrían aprender mucho de estos vigilantes bonaerenses, y ganarían siguiendo su ejemplo" (45). Buenos Aires se destaca por la ordenada urbanidad de sus costumbres, que juzga civilizadas por la ausencia de gritería en las calles, desmanes y groserías públicas. La cortesía y la moderación, dice, son "todas demostraciones de cultura, de eso que llamamos buena crianza. Cualquier extranjero, de cualquier parte, que llegue a Buenos Aires puede tomar en esta ciudad lecciones de urbanidad en la vía pública” (45).

Sin embargo, Trinidad Pardo de Tavera señala un punto desfavorable observable en la gran capital: la enorme mendicidad que se observa en sus calles. Sin proporcionar ninguna explicación social al fenómeno, lo explica mediante un acendrado prejuicio nacional: "Puede decirse que la mendicidad es una plaga hispano-italiana. Allí donde se habla alguna de estas lenguas, florece la mendicidad en todo su esplendor" (42). La mendicidad sólo despierta en el viajero una indignación moral, sin buscar otra explicación que en los meros reflejos culturales ibéricos e itálicos.

Viajero de encumbrada posición social e intelectual, el filipino frecuenta a todas luces personas de su misma condición (aunque no hace ninguna referencia explícita a sus relaciones sociales durante su estancia). Describe los sitios propios de la alta sociedad porteña, en donde desfila la "High Life", como el lujoso y selecto Jockey Club de Buenos Aires, o el hipódromo de la ciudad y su cortejo de vida mundana. En los elegantes salones del primero "se admiran cuadros de Goya, Sorolla, Pradilla, Bouguereau y otros", junto con "la naturalidad de maneras y de expresión de la concurrencia [del hipódromo de Palermo], muy distinta de la que se observa en Europa” (46). Para rematar más adelante su explicación de la diferencia entre la altanería de clase (burguesa o aristocrática) del viejo mundo y la civilización de costumbres modernas:

[Europa,] en donde la gente de alta condición social hace alarde de su altanería, usando modales dictados por la más ciega vanidad y por el afán de aparentar cada uno más elevada calidad que los otros. En la sociedad argentina, por más que los franceses la acusen de rastacuerismo, no hay nada que pueda justificar rastacuerismo, sino, al contrario, una facilidad de maneras 
distinguidas que seduce al instante, y que puede servir de modelo a otras sociedades que, preciándose de más cultas, son sencillamente víctimas de la vanidad y el orgullo de tiempos pasados (46)

Resulta evidente que este juicio es pronunciado por un observador de encumbrada condición social que, aun viviendo en Europa, definitivamente no pertenece a la sociedad europea; estas palabras expresan el orgullo social de un notable criollo filipino que se identifica con el designio histórico de la clase patricia argentina: construir una nación civilizada moderna a través de la acción directriz de la élite. Y la civilización se verifica en los modales y las costumbres sociales adoptadas por un pueblo educado. Trinidad Pardo de Tavera se identifica con este destino de la aristocrática dirigencia política argentina: aspira a que la élite insular de su propio país logre asumir en el futuro un destino tutelar semejante. La Argentina liberal, abierta y cosmopolita, encarna en aquellos años la posibilidad de la modernidad civilizada dentro de la cultura hispánica; este mismo destino Pardo de Tavera lo desea para su país, aunque las condiciones y los medios para alcanzarlo sean diferentes.

\section{Observaciones sobre el modelo social y económico argentino}

El progreso excepcional de la Argentina obedece según el observador filipino a tres factores conjugados. 1) La riqueza social y económica representada por la empresa de inmigración masiva puesta en marcha por la Argentina desde 1862. 2) La disponibilidad que tiene el Estado nacional de territorios fiscales, ofrecidos en venta o arrendamiento a los colonos recién llegados al país, para un cultivo extensivo. 3) La buena gestión política e institucional de la inmigración y de las infraestructuras del país, en constante desarrollo y adaptación a las demandas del mercado mundial. Veamos el detalle de estos elementos esenciales.

Trinidad Pardo de Tavera destaca la política practicada por la élite gobernante de puerta abierta para con los inmigrantes, sin discriminación de orígenes, credo, raza y sin condiciones de admisibilidad (esto es, sin practicar una inmigración selectiva). La promoción de la inmigración masiva 
está inscripta en la Constitución federal de la Argentina y es promovida mediante una Agencia Nacional de Inmigración con delegaciones activas en toda Europa. Sólo dos países practicaban semejante política de atracción de los inmigrantes: los Estados Unidos y la Argentina. Este último caso era el único entre las jóvenes naciones hispanoamericanas. "Al emigrante se le recibe como a un amigo; más todavía, como un bienhechor". Y el inmigrante "sabe que su cualidad de extranjero no es un obstáculo, sino una facilidad para su desarrollo en el país" (46). La fuerza de trabajo aportada por los inmigrantes es el factor esencial para el desarrollo de la economía y el engrandecimiento de la nación. Sin este aporte extranjero el país no conocería el rápido progreso material. Por tal motivo los diferentes gobiernos se empleaban desde hacía cincuenta años en promoverla y acogerla debidamente, creando las estructuras adecuadas para recibir a los inmigrantes.

El viajero filipino describe las infraestructuras para recibir a los recién llegados, a través del 'Hotel de Inmigrantes' de la Dársena Norte del puerto de Buenos Aires, y asimismo en Rosario y Bahía Blanca, donde los desembarcados podían quedarse durante cinco días con sus gastos cubiertos, antes de ser dirigidos según sus aptitudes al destino inicial asignado siguiendo las necesidades de mano de obra. Las instalaciones eran sumamente modernas. Los enfermos podían permanecer más tiempo, o eran enviados de ser necesario a los recintos de cuarentena. "El departamento de inmigración del gobierno se ocupa de colocar aquellos que llegan sin destino. Si alguno desea residir en provincias, el gobierno le costea el transporte hasta el lugar elegido, donde, hasta diez días después de su llegada, es mantenido todavía a costa del Estado" (47). Trinidad Pardo de Tavera señala una transformación observable en los recién llegados:

El cambio es más profundo todavía, porque la inteligencia se ha despertado [en el inmigrante], y todo el bienestar y el progreso material que les rodea ha influido en las condiciones morales, argentinizando y haciendo un hombre moderno del labriego mísero e ignorante de años atrás. (47) unificar el criterio de la puntuación antes o después del corchete.. 
La producción ganadera y agrícola se encuentra en un periodo de profunda transformación, diversificación y expansión. Los grandes propietarios se han enriquecido con la incorporación de tierras productivas (cuya extensión parecía ilimitada), pero sobre todo por el hecho que han comprendido a tiempo que para la modernización productiva de estas tierras requerían del continuo aporte de mano de obra extranjera para su explotación. Han mejorado las razas ganaderas, intensificado la producción, y han construido inmensos frigoríficos para la exportación masiva de carne al mercado mundial. Pardo de Tavera tiene ocasión de visitar dos inmensos frigoríficos en Buenos Aires y en La Plata, acompañando a un veterinario sueco enviado por el reino de Suecia para realizar controles sanitarios. La descripción de los mismos es sumamente detallada, así como las estadísticas de la evolución vertiginosa del stock ganadero del país (rubro que le interesa particularmente al viajero) (48-49).

La agricultura extensiva avanza sobre tierras antes destinadas al pastoreo ganadero, ahora explotada por los labriegos al servicio de los grandes propietarios, y asimismo la posibilidad de establecerse por su cuenta como colonos o arrendatarios. "Como una tierra no vale nada mientras no haya quien la cultive, por todas partes hay una gran demanda de inmigración, y para atraerla se ponen en venta pública terrenos parcelarios según el sistema de remates” (49), explica Trinidad Pardo de Tavera. Con los conocimientos aportados consigo por los labriegos inmigrantes, y el deseo de progresar, se diversificaron las industrias agrícolas (vitivinícola, fruticultura, aceites, etc.). La perforación de pozos arlesianos y la construcción de nuevos regadíos contribuye a la expansión agrícola en una llanura (la pampa) que parece no tener límites y que puede acoger por igual grandes propiedades como pequeñas colonias o arrendatarios. Afirma que "toda aquella magnífica tierra sufrió una transformación colosal que enriquecía a la vez a quién trabajaba y al dueño sedentario que, al aumentar el valor de su propiedad, tenía la feliz ocurrencia de correr a Europa, sin pérdida de tiempo, en busca de los placeres de sus grandes ciudades" (49).

La carrera productivista de la explotación agrícola y ganadera ha generado una euforia sin duda excesiva. Trinidad Pardo de Tavera, observador 
avisado, advierte los riesgos inmediatos de tal desenfreno y escalada inflacionaria del valor (basada en el laissez faire de los fisiócratas). Sentencia: “Todo el mundo especula en el valor de las tierras. Ese es el gran peligro en Argentina: la especulación, que inquieta a todos, por lo incierto y ficticio de lo que sirve de base para calcular el 'porvenir' de una tierra” (50). La disminución abrupta de la inmigración debido al inicio de la guerra europea y mundial, desatada el 28 de julio de 1914, propició una repentina caída de los valores de las tierras, que sin el aporte de mano de obra extranjera no podían ya mantener sus valores especulativos. "El precio de la tierra sube, en la esperanza de que afluirán los inmigrantes, porque sin ellos nada adquiere valor ni consolida el adquirido” (50). Esta especulación está al origen de las crisis que recurrentemente conoce la Argentina, vinculadas a los ciclos de valorización ficticia (y fundada en el continuo aporte de nueva mano de obra).

Pardo de Tavera es perspicaz para comprender el funcionamiento económico del país, captando los mecanismos esenciales de la producción y los precios (elevados), y el modo en que se forman artificialmente estos últimos, mediante el coste en alza de la mano de obra. Comprende en definitiva cómo se forman los precios independientemente de las leyes del mercado; como por ejemplo la producción frutícola abundante, puede llegar al mercado a precios elevados resultado de la "escasez artificial" manipulada por los productores (que acopian y retienen la producción para elevar los precios con menos trabajo). De modo que no sólo la ley de la oferta y la demanda regula los precios, sino que éstos se falsean mediante la restricción programada de la oferta, y por el hecho que, en el contexto argentino de la época, "el precio del trabajo podía fijarlo el mismo que lo producía” (50). Señala Pardo de Tavera que de esta forma los salarios tienden a nivelarse artificialmente por lo alto, pues todos los que trabajan "tienden a nivelar el valor del trabajo" por cualquier medio. "El jornal es muy elevado, lo mismo que todos los salarios; pero también el precio general de la vida es sumamente alto. [...] En consecuencia, la vida es allá carísima” (50).

La balanza comercial de Argentina tiene entonces saldo favorable porque exporta mucho e importa poco, entrando más dinero del que sale. Y la mano de obra extranjera cuenta como uno de los principales rubros de las 
importaciones. El flujo de capitales, sobre todo británicos, es de "abundancia ilimitada” e inyecta toda la economía nacional, provincias y municipios, conjuntamente con el crédito privado. El filipino constata un hecho entonces asombroso: "yo no conozco un país donde, para su desarrollo económico, primero haya concurrido el capital y luego... la mano de obra" (51), provocando un ciclo virtuoso que, multiplicado por la afluencia inmigratoria, atrae nuevos capitales de Europa. "La mano de obra y el capital extranjero han sido los factores de la prosperidad de aquel país” (51). El viajero vislumbra que la guerra mundial provocará el incremento de los flujos comerciales y de capitales con los Estados Unidos, en detrimento de Europa. A pesar de las resistencias culturales y la desconfianza política de los gobiernos argentinos, el acercamiento con la economía estadounidense parece ineluctable pues "la pobre Europa cesa su producción industrial reproductiva para dedicarse por entero a la producción destructiva" (51).

Comparando a la Argentina con Filipinas, Trinidad Pardo de Tavera se interroga sobre el pasado y el presente de ambos países. Sostiene que el sistema económico colonial era semejante en ambos, empleando para calificarlo el término de "economías de secuestración tutelar" (51-52); incluso asevera que éste era más desfavorable para Buenos Aires que para Manila. Los destinos de ambas regiones bifurcan definitivamente durante el siglo XIX, por la "sagacidad política" de los "grandes hombres" que han creado la Argentina a partir de la independencia en 1810, llamando al concurso de la población extranjera desde el inicio. "Aquellos fundadores de la Nación Argentina tuvieron la sagacidad de descubrir toda la importancia y toda la trascendencia de la inmigración para el desarrollo de su patria” (52). Entre los "grandes hombres" figuran dos expresidentes, Domingo F. Sarmiento y Carlos Pellegrini. El primero desarrollará de modo exponencial el sistema educativo nacional, vector esencial del desarrollo humano del país y zócalo fundamental del desarrollo económico y social de la nación. Sarmiento, dice Pardo de Tavera, "creía, como los padres de los Estados Unidos, en la omnipotencia redentora de la educación” (52).

Para el filipino, uno de los secretos de la Argentina moderna es el entendimiento mutuo entre los "hijos del país" y los "extranjeros". Los argen- 
tinos nativos nunca abrigaron recelos ni temores ante los recién llegados. Por el contrario, la buena estrella y mejor fortuna de los locales dependía estrechamente del flujo de inmigrantes para valorizar la tierra y acrecentar la producción. Inversamente, "los inmigrantes no han tenido tampoco que temer la competencia de los hijos del país, cuyas aspiraciones principales, y para la mayoría, única, son gobernar y tener en sus manos la autoridad política" (51). De suerte que, en los hechos, existe una división social armoniosa entre inmigrantes y nacionales, a condición de que los primeros no reclamen una representación política en la gestión de los asuntos públicos, y que los segundos mantengan el monopolio de la administración política y social del país.

Lo que el viajero filipino no puede observar en 1914 es que esta ecuación o pacto social tácito entre la plebe extranjera y la élite gobernante del país estaba a punto de desmoronarse por la creciente y acuciante presión de los primeros sobre los segundos. Los inmigrantes, y sobre todos sus hijos, ya ciudadanos argentinos, reclamaban para sí una serie de derechos sociales y una creciente representación política, apertura que no estaba contemplada en el pacto fundador de la Argentina liberal y oligárquica, vigente desde 1862. En efecto, el flujo migratorio en Buenos Aires y otras urbes, forjó una clase obrera con aspiraciones políticas y nueva organización sindical, que desde las últimas décadas del siglo XIX pujaba por una participación política y social con reivindicaciones de clase, cuyos reclamos eran difícilmente audibles en la república oligárquica forjada por la Generación de 1880 y los gobiernos subsiguientes. Las reformas del sistema político estaban produciéndose en el mismo instante en que Trinidad Pardo de Tavera visita el país, pero este fenómeno no era observable para él. En efecto, el presidente Roque Sáenz Peña había hecho votar por el Congreso, en febrero de 1912, la ley que estableció el voto universal, secreto y obligatorio para los ciudadanos mayores de 18 años. Esta ley tenía por objetivo esencial ampliar la base social de la participación ciudadana en la política, proporcionando una mayor legitimidad a los nuevos gobiernos. También, al tiempo que satisfacía los reclamos de la oposición (la Unión Cívica Radical y, en menor medida, los Socialistas), buscaba mediante esta ley de afirmación democrática quitarles apoyo a los 
sectores más contestatarios a la extensa hegemonía del Partido Autonomista Nacional. Este cálculo no fue sin embargo favorable a los conservadores: en las primeras elecciones de 1916 realizadas con este sistema, triunfa Hipólito Yrigoyen, candidato de la oposición (la Unión Cívica Radical).

Esta incapacidad por parte del filipino para observar ciertos fenómenos sociales determinantes no sólo se debía a su calidad de visitante temporario, no residente; creemos que esta ceguera social era también atribuible a cierta limitación de clase. Esto significa que, por su condición de miembro distinguido de la élite criolla filipina, se identificaba naturalmente con la clase dirigente argentina (los "hijos del país", que administraban el país como sus haciendas), como para penetrar en sus observaciones otra realidad social: la realidad de la nueva clase obrera que sin duda escapaba a su mirada escrutadora. Numerosos son los pasajes de su crónica de viaje en donde se opera una identificación apenas disimulada con la "sagacidad política" de los "grandes hombres" argentinos. Dicha identificación recurrente constituye no sólo un reflejo clasista de filipino encumbrado, sino una identificación con un modelo de hispanidad exitoso y moderno, que a sus ojos representaba "el camino" a seguir por su propio país (aunque el viajero se abstiene con mucho de establecer paralelos más profundos en esta dirección). Podemos suponer que el perímetro de sus frecuentaciones sociales se restringía a los miembros de la élite porteña (Jockey Club, el hipódromo, la vida mundana de la Avenida de Mayo, los barrios residenciales, el balneario de Mar del Plata al que asistía la high society); en cualquier caso, no hay registro alguno en sus recuerdos de la vida social en los barrios populares. Trinidad Pardo de Tavera es en realidad testigo del fin de la república conservadora y oligárquica, sin avizorar el nuevo rumbo que estaba emprendiendo el país, con su consiguiente carga de incertidumbre.

Observa, sin criticarlas en absoluto, las condiciones en que se ejerce el poder en la república conservadora:

Los hijos del país son muy aficionados a los cargos públicos. Todos los empleados del gobierno son 'nativos', como decimos en Filipinas. Los puestos más importantes, incluso la presidencia, están monopolizados por un reducido número de familias, por una oligarquía compuesta de una base 
de antiguos argentinos fundida con elementos nuevos traídos por la inmigración redentora (53).

Este retrato se completa poco más adelante con una descripción edénica y benevolente de esta nobleza criolla, caracterizada a su juicio por el desinterés y el altruismo, y aderezada por la gloria personal como rasgo psicológico:

Regularmente, los miembros de esta oligarquía no buscan el poder para enriquecerse, aunque hay excepciones, porque casi todos son ricos, sino por el placer de ejercer el poder, por ser algo y alguien en la vida política de su país. Todos los hijos del país son amantes del progreso y aceptan aquello que, a su juicio, puede mejorar el estado material y moral de sus compatriotas (53).

Completa a continuación el panorama con un rosario de cualidades y atributos positivos: "Son inteligentes, educados, ambiciosos y refinados. Saben distinguir el oro del oropel y la verbosidad del talento” (53). Esta aristocracia patricia se afirma en dos condiciones esenciales: "el dinero, que da rango social, y el cargo oficial, que da rango politico" (53). Tras este lenguaje sobrio y preciso, Trinidad Pardo de Tavera deja fluir toda su admiración por esta clase dirigente argentina, cuyas cualidades (piensa él) eran semejantes a la suya y a la de aquellos filipinos de su condición.

En su descripción de la Argentina moderna Pardo de Tavera señala además otro factor de peso: la existencia de una multitud de autoridades sociales en las provincias y municipios, de responsables locales calificados, capaces "de influir en todas las demás manifestaciones de la vida argentina” (54). Su papel resulta decisivo, según él, en la evolución de la política nacional. Dicho entramado socio-político sustenta la estabilidad del país, distinguiéndolo de "la vida de perturbación política y de gobierno de la fuerza, común a las repúblicas latinoamericanas” (54). Estas autoridades locales son los garantes del orden y la legalidad social. Sin estas autoridades intermedias, que ejercen un importante rol de mediación social, "la Argentina sería otra pequeña república de pronunciamientos y golpes de estado militares, en un estado de guerra civil permanente, en donde los puestos oficiales son 
los únicos alicientes de la ambición. Donde no se conocen las autoridades sociales, sólo se lucha por la posesión de la autoridad política” (54). Pardo de Tavera detalla luego extensamente las carencias políticas e institucionales de esas otras repúblicas latinoamericanas "impermeables" a la inmigración extranjera y adictas a un nacionalismo de pacotilla que alienta la desconfianza hacia los extranjeros, y donde las oligarquías ejercen un derecho predador y confiscatorio hacia su propia población: "una oligarquía acapara el gobierno y explota a sus anchas el patriotismo de la masa ignorante y pobre que conquista, por la retórica, el soborno y la fuerza" (55). Indica el viajero que esta opinión es en parte aplicable al caso de Filipinas, hostil a la inmigración y cuyo pueblo está encerrado en su propio tipo (56). Traducido al ámbito social y político filipino, Pardo de Tavera opera (y convoca) una identificación tácita de su país con la administración estadounidense que, a su juicio, desempeña en el archipiélago un papel progresista y modernizador.

\section{El porvenir radiante}

Trinidad Pardo de Tavera se detiene extensamente en el análisis de un conflicto internacional de gran trascendencia a comienzos del siglo XX: el bloqueo naval anglo-italo-germano en diciembre de 1902 al puerto de La Guaira en Venezuela. El interés de este episodio le permite sopesar la creciente importancia diplomática de la Argentina en el contexto de la época, en la que la potencia estadounidense todavía estaba afirmándose en Latinoamérica mientras la razón imperialista europea todavía gastaba sus últimos cartuchos en la región. El bloqueo finalmente se resuelve con la firma de un protocolo por ambas partes, rubricado en Washington el 13 de febrero de 1903.

Durante el incidente, la Argentina, a través de su ministro de Relaciones Exteriores, José María Drago, adopta una clara posición contraria al intervencionismo por el cobro de deudas financieras. Líder del grupo conocido por la sigla $\mathrm{ABC}$ - que designa a la Argentina, Brasil y Chile-, la diplomacia argentina avanza el criterio de que "ninguna ley civilizada acuerda a un hombre rico o fuerte el derecho de erigirse en sí mismo en juez y ejecutor del culpable pobre o débil” (56). Ante la ambigüedad estadounidense, que no quiso aplicar la Doctrina Monroe ante este caso de intervención beligerante 
europea (por juzgar que la misma no se aplicaba a los casos de cobros de empréstitos), la posición firme de José María Drago en los foros internacionales, fundada en la Doctrina Calvo ${ }^{10}$, erigió a la Argentina en protectora de las repúblicas latinas. La mayor parte de los países, aún los beligerantes europeos, terminaron por aceptar este principio. Según el filipino, el incidente venezolano "ponía de relieve la capacidad internacional de la diplomacia argentina". De modo que "el mundo civilizado contemplaba una república latinoamericana que lograba hacer triunfar una doctrina que ponía a salvo no sólo la dignidad de las repúblicas hermanas, sino también los fueros verdaderos de la justicia” (57).

Los sucesos venezolanos motivaron el Corolario Roosevelt de 1904 a la Doctrina Monroe, corolario que inaugura la etapa intervencionista de los Estados Unidos en Hispanoamérica. Frente a las convulsiones provocadas por la revolución mexicana de 1910, Theodore Roosevelt buscará consenso para intervenir en México, hallando un rechazo tajante por parte de la Argentina, que observaba con profunda desconfianza la extensión de la hegemonía paternalista de Estados Unidos en la región. Los acontecimientos mexicanos confirmaban una vez más el liderazgo diplomático de la Argentina en aquellos años y, para Trinidad Pardo de Tavera, este liderazgo era otra de las realizaciones clarividentes de los "grandes hombres" de la Argentina en el plano internacional.

Para el visitante filipino el porvenir de la Argentina es promisorio pues la modernidad del país en todos los rubros la colocaba a la cabeza de las naciones progresistas. Juzga que su economía agroexportadora e incipiente industria la ponía al abrigo de las crisis, pues los cuatro artículos principales de exportación (carne, cereales, cueros, lana) eran productos de consumo universal. El punto débil de su modelo económico era la continua necesidad de incorporar mano de obra extranjera, interrumpida en 1914 por la guerra mundial en Europa. "Las tierras todavía no aprovechadas y la transformación del cultivo en métodos intensivos, ofrece a la agricultura un porvenir inmenso" (59). Pardo de Tavera sostiene que una vez finalizada la contienda mundial la emigración europea hacia los Estados Unidos y la Argentina se 
reanudará e intensificará (59) aportando a estos países nuevos brazos y una cuota de templanza moral.

Las características observadas por el filipino en el pueblo argentino y las virtudes de su clase dirigente, conjugado con la educación y la prosperidad material, la han elevado a un rango único entre las naciones hispanas, constituyendo con Francia los únicos países resueltamente cosmopolitas y abiertos del mundo latino. Avanza que el "tipo argentino", pese a las virtudes heredadas de Europa, ha sabido forjar un tipo de humanidad propio al Nuevo Mundo, fundado en la sencillez y la franqueza.

Tan sólo dos notas destempladas del filipino empañan el horizonte de este retrato idílico. Son dos aspectos que forman parte del mismo fenómeno: la excesiva cercanía cultural de la Argentina con Europa, e inversamente, su distancia cultural y excesiva reticencia política para con los Estados Unidos. Según Pardo de Tavera, si bien Europa ocupa un sitio indiscutido en cuanto a civilización y cultura se refiere, los Estados Unidos encarnan el verdadero ideal del espíritu democrático moderno, instancia en la que ninguna nación del Viejo Mundo le hace sombra. Para el filipino, el derrotero progresista de la Argentina sólo puede engrandecerse yendo al encuentro de los Estados Unidos y, en proporción directa, alejándose de sus orígenes europeos.

Antes de comentar una cita sobre los extranjeros del presidente Roque Sáenz Peña, señala nuestro viajero:

Cuando visité Buenos Aires, el señor Sáenz Peña era presidente de la República. Sus compatriotas le discutían mucho por sus humos aristocráticos, adquiridos en Europa, a donde va tanto argentino a perder las cualidades más apreciables de su carácter: la sencillez y la franqueza. En el cuerpo diplomático de Europa se refinan, sin duda alguna, los argentinos, pero, desgraciadamente, no se democratizan. Al contrario, por imitación, aceptan y adquieren humos y actitudes aristocráticas que luego sostienen [reproducen] en su país (53).

El contacto estrecho con Europa forja el carácter arrogante y aristocrático; el contacto estrecho con los Estados Unidos forja en cambio el carácter genuinamente democrático. 
Trinidad Pardo de Tavera juzga que las razones para desconfiar del imperialismo ascendente de los Estados Unidos son valederas y atendibles. Pero éstas no justifican sin embargo la tenaz distancia teñida de recelo que la Argentina tiene hacia los Estados Unidos. Más allá de los slogans diplomáticos que han fomentado la reticencia y la desconfianza mutuas ("América para los americanos" sostenían Monroe y Roosevelt; "sea América para la humanidad” replicó Sáenz Peña), el acercamiento de Argentina con la gran nación del Norte le parece ineluctable. Residente en Francia, Pardo de Tavera observa los límites de esta inspirada frase de Roque Sáenz Peña que supo cosechar aplausos entre los hispanoamericanos, tanto por lo dicho como por lo que soslayaba o dejaba entrever. Pardo de Tavera señala con las siguientes palabras, de tono incisivo y crítico, que denotan su mirada filipina y asiática:

Como frase, es sin duda bonita: como sentimiento es más poética, más altruista, más amplia que la otra, pero, en el fondo, ¿qué significa? Palabras, palabras, palabras. Ni literal ni legalmente era cierto lo que decía el argentino porque la propia Constitución de su patria, lo mismo que todos los documentos oficiales relativos a la inmigración dicen siempre 'favorecer la inmigración europea', y, en verdad, la humanidad no reside exclusivamente en Europa. En medio de todas las fórmulas de altruismo, los argentinos rechazan la emigración de raza amarilla, de manera que eso de 'humanidad' es algo así como una licencia poética, y nada más (53).

Asimismo, el viajero restituye una verdad indiscutida por encima de la batalla de slogans políticos, pues por cierto 'América para los americanos' no expresa la idea de "cerrar las puertas a los individuos sino a las naciones", y señala de paso que cuando los argentinos abren sus puertas a la humanidad, "es con la esperanza de que la humanidad que allá penetre se haga argentina" (53).

Trinidad Pardo de Tavera observa que, tras esta contienda diplomática y política, la verdadera razón es que los argentinos "quieren la hegemonía del mundo latinoamericano [...]. Actitud diplomática que revelaba claramente el concepto que tenía de su deber nacional e internacional en el Nuevo Mundo" (59). De esta actitud legítima, "puede asegurarse que Argentina comprende 
que su papel será organizar la resistencia contra el imperialismo de Estados Unidos en toda la América latina” (59).

Los Estados Unidos representaban un tope absoluto a las aspiraciones hegemónicas argentinas en Hispanoamérica. Confiado en el porvenir auspicioso de la nación sudamericana, Pardo de Tavera adopta una posición realista y sabe que esta disputa por el liderazgo no se dirime en los salones diplomáticos o mediante debates y argucias morales, sino en el plano de la simple supremacía económica. Tal una sentencia, concluye con estas palabras su extenso informe sobre la Argentina: "Yo digo que la hegemonía política, literaria, artística, industrial y comercial, pertenecerá al más poderoso, y el más poderoso será... el más rico, el de mayor desarrollo económico” (59). De seguro que, en el pudor o falsa incertidumbre de los puntos suspensivos, el autor había puesto como ganador a los Estados Unidos.

\section{Conclusión}

A la luz de la historia posterior de la Argentina tras la visita de Pardo de Tavera en 1914, sus opiniones entusiastas resultan hoy excesivas. Sin caer en juicios exagerados, la historia argentina del siglo XX parece desmentir en forma sistemática las cualidades y logros otrora atribuidas al país, a su pueblo y a la clase dirigente.

Fácil sería demostrar que las impresiones de Trinidad Pardo de Tavera eran erróneas o superficiales en muchos de sus aspectos esenciales. Pero estos recuerdos de un viajero filipino ilustrado no aspiraban a completar un exhaustivo estudio histórico, económico o sociológico del país. Sus observaciones pretendían apenas bosquejar un retrato lo más fidedigno posible para sus connacionales filipinos. Indicamos al inicio las precauciones tomadas por el autor en su carta de remisión al editor de The Philippine Review en Manila. Considerados bajo esta luz, sus recuerdos son bastante ajustados (o lo son parcialmente) con la realidad. Una miríada de juicios positivos semejantes a los de Pardo de Tavera pueden compendiarse en otros testimonios, especialmente entre los viajeros europeos. Su visita corresponde con el punto culminante de la nación liberal y oligárquica en la Argentina, en el cénit de máxima confianza y esplendor. Para dimensionar estas circunstancias 
históricas alcanza con cotejar estas opiniones positivas con las que, en la misma época, los observadores internacionales tenían sobre otros países de América, Europa o Asia. Las estadísticas económicas globales indican que la Argentina ocupaba en 1913 la quinta posición en el mundo por su PIB per cápita, delante de Alemania y Francia (Maddison 153).

En el testimonio de Trinidad Pardo de Tavera hallamos tres limitaciones interpretativas fundamentales: históricas, sociales y políticas.

Haciendo excepción de algunas pocas comparaciones con las Filipinas durante el período colonial (51), el viajero no menciona las coordenadas esenciales de la expansión territorial del Estado argentino en el siglo XIX, base del enriquecimiento nacional (Gaignard). Nunca se interroga sobre cómo tanta tierra se halla disponible para la especulación, ni cómo se la conquistó mediante una guerra cruenta contra los indígenas del país que fueron exterminados y acorralados en remotas reservas. Oficialmente, la guerra contra el indio en la Argentina finaliza en 1916, es decir que durante la visita de Trinidad Pardo de Tavera las acciones militares contra la resistencia indígena no habían cesado todavía (sobre todo en el Noreste del país, en la región fronteriza con el Paraguay).

Los comentarios sobre la situación argentina en el plano social constituyen otra laguna estructural de sus testimonios, concentrados exclusivamente al análisis de la inmigración. La aceptación e integración de la población extranjera es descrita en forma edénica y resulta en gran medida ilusoria. Si bien las estadísticas y datos proporcionados por Pardo de Tavera son fehacientes, la realidad de la integración social y política de las masas extranjeras fue mucho más conflictiva de lo que el filipino deja suponer. Ni todos los inmigrantes eran sumisos y obedientes a la ley del país de acogida, ni todos los nativos (al igual que los miembros de la clase gobernante) eran 'inmigracionistas' convencidos y militantes (Bertoni 166-172). El nacimiento del nacionalismo argentino como expresión política y cultural, es concomitante a los años en que la nación liberal se afirma y expande, es decir, el país de la Generación de 1880, cuya obra es celebrada por Pardo de Tavera en las figuras de Domingo F. Sarmiento y Carlos Pellegrini. Numerosas voces se alzaban contra la inmigración, por considerarla excesiva. Lo hemos indicado antes: 
la inmigración masiva tuvo por consecuencias inmediatas el nacimiento de los reclamos sociales, la emergencia de la acción sindical clasista y radical (la federación sindical anarquista, FORA), de los movimientos políticos contestatarios (UCR) y/o revolucionarios (partido Socialista, Anarquistas, etc.). Numerosas investigaciones históricas han analizado en detalle esta cuestión y resulta imposible sintetizar y desarrollar aquí estos aspectos.

Por último, los comentarios políticos de Pardo de Tavera son débiles porque no penetra nunca los meandros de la vida política argentina; se mantiene en la superficie, sin captar su complejidad. La descripción de la clase política argentina -de raigambre patricia y elitista, es retratada como una clase dirigente sin fisuras internas, como un bloque homogéneo dilatado en el tiempo-, resulta ser un fenómeno muy alejado de la realidad histórica. La clase dirigente fue muy contestada en la vida política argentina hasta 1916 (se produjeron al menos tres revoluciones encabezadas por la Unión Cívica Radical, en 1890, 1893 y 1905, y otras muchas huelgas obreras reprimidas por un baño de sangre), sin contar que las crisis posteriores a 1914 serán aún más virulentas. Otro tanto sucede con la economía, tambaleante, que atravesó numerosas crisis financieras nacionales e internacionales, debido al exceso de especulación (esto sí fue señalado por el viajero). Los aspectos positivos atribuidos por Pardo de Tavera al desarrollo argentino aparecen descritos como un mérito unilateral de su clase dirigente (la obra de los "grandes hombres"). En su entusiasta identificación con las medidas y acciones políticas llevadas adelante por la dirigencia liberal argentina trasunta en realidad una identificación clasista evidente por parte de aquel que proyecta su propio deseo -aspirando a que algún día, en Filipinas, los "grandes hombres" se despierten a un destino semejante-. Los emprendimientos de esta clase dirigente son vistos con benevolencia por Trinidad Pardo de Tavera, enunciando escasas críticas y ninguna objeción. Las acciones de esta clase política oligárquica revelan una suerte de teleología milagrosa, como si estos grandes hombres hubiesen sido tocados por una vara mágica. Las realizaciones de la modernidad son el milagro del capitalismo global: "En una palabra: aquella antigua colonia del tipo de sociedad militar y religiosa, es hoy una república moderna del tipo de sociedad científica y productiva que se afana detrás del 
peso" (54). Entre la época colonial y la nación moderna hay una gran elipsis en los testimonios de Pardo de Tavera; y esta elipsis constituye lo esencial de las disputas políticas argentinas del siglo XIX: las luchas entre federales y unitarios, entre liberales y conservadores, entre partidarios y opositores a la federalización de la ciudad de Buenos Aires y la nacionalización de su aduana, y en fin, entre nacionalistas y cosmopolitas, aparecen silenciadas en su testimonio. 
1. Let us mention the American dancer Isadora Duncan, the French actress Marguerite Moreno, to high-profile intellectuals, writers and journalists such as Rubén Darío, Enrique Gómez Carrillo, Anatole France, Jean Jaurès, Ramón del Valle Inclán, Jacinto Benavente, Rafael Blasco Ibáñez, Enrico Ferri, without forgetting the engineer Guglielmo Marconi or the physicist Albert Einstein.

2. Desconocemos la fecha exacta de su viaje y estancia en la Argentina, pero por algunos indicios del relato deducimos el año indicado. Por ejemplo, dice: "cuando visité Buenos Aires, el señor Sáenz Peña era presidente de la República” (53). Roque Sáenz Peña fue elegido presidente para el mandato 1910-1916, pero, de frágil salud toma licencia por enfermedad y fallece el 9 de agosto de 1914, siendo sustituido por el vicepresidente Victorino de la Plaza. Inferimos que Trinidad Pardo de Tavera permanece en el país hasta antes del fallecimiento de Sáenz Peña.

3. Las "Provincias Unidas del Río de la Plata" - futura República Argentinainician su gesta de emancipación el 25 de mayo de 1810. La particularidad de esta independencia, declarada oficialmente el 9 de julio de 1816, es que no conoce reverses y vuelcos contrarrevolucionarios como en otros sitios de la América hispánica (v. gr. Chile, Perú, Venezuela, México). Los festejos en 1910 del Centenario de la Argentina duraron largos meses y constituyeron una "vitrina oficial” de los progresos realizados por la nación en su primer siglo de existencia. Mediante estos festejos el gobierno enarbola de cara al mundo el triunfo del proyecto liberal, en su cénit institucional y económico. En la historiografía argentina y el imaginario nacional el Centenario es referido a menudo como la "Edad de Oro" del país.

4. Trinidad Hermenegildo Pardo de Tavera, "Recuerdos de Argentina", The Philippine Review/Revista Filipina, Manila, Feb. 1916, v. I, n², 42-59.

5. Para una evaluación de su obra hasta el año 1913 y su papel destacado en la cultura filipina, remitimos al estudio: cf. Epifanio de los Santos Cristóbal, Trinidad H. Pardo de Tavera, Manila, Imprenta Cultura Filipina, 1913. Esta obra reúne una serie miscelánea (50-183) de conferencias, discursos, ensayos y entrevistas publicados por Pardo de Tavera en la prensa manileña entre los años 1906 y 1912, obra dispersa que traduce algunas de las ideas políticas destacadas de Trinidad Pardo de Tavera sobre identidad, cultura, política, economía y educación en Filipinas. El volumen reúne los trabajos siguientes: "El alma filipina" (17 de mayo 1906, 50-66), "Autoridades sociales" (17 de abril 1909, 66-77), "La imprenta en Filipinas” (20 de junio 1911, 77-92), “El Japón moderno” (octubre 1912, 99-111), "Porqué se suicidó el General Nogi” (28 de septiembre 1912, 112-116), "La nueva mentalidad filipina” (14 de noviembre 1912, 116-138), 
"Resultados del desarrollo económico de Filipinas" (noviembre 1912, 138-171), "Desarrollo industrial" (agosto 1911, 171-178), "Por dónde y cómo debemos ir" (febrero 1912, 178-183). Resultaría de gran interés comparar algunos de estos ensayos con el testimonio de su viaje a la Argentina, pues existe una profunda proximidad temática que nos permitiría analizar el alcance de algunas de sus preocupaciones entorno a la modernidad filipina y su proyecto nacional, y los avatares de la modernización institucional, política, social y de desarrollo económico vinculados a este último. Pero semejante esfuerzo excede las dimensiones del presente trabajo, mereciendo sin duda un estudio específico centrado en el pensamiento político de Pardo de Tavera y su concepción de la modernidad.

6. Mencionemos a la bailarina estadounidense Isadora Duncan, la actriz francesa Marguerite Moreno, a encumbrados intelectuales, escritores y periodistas como Rubén Darío, Enrique Gómez Carrillo, Anatole France, Jean Jaurès, Ramón del Valle Inclán, Jacinto Benavente, Rafael Blasco Ibáñez, Enrico Ferri, sin olvidar al ingeniero Guglielmo Marconi ni al físico Albert Einstein.

7. Para simplificar citamos este ensayo con las referencias directas a la página entre corchetes.

8. Este aspecto se vincula directamente con el tratamiento de la cuestión racial dentro de la modernidad argentina. La concepción racial del proyecto de civilización nacional argentino, tras el sometimiento violento o exterminación de los indígenas, excluyó toda política de integración de los pueblos nativos del "crisol de razas" publicitada en paralelo por el Estado como elemento constitutivo del "guiding fiction" sobre la identidad nacional y el cosmopolitismo. No podemos estudiar en este ensayo la cuestión racial en Argentina, pero destacamos su importancia fundamental, y señalamos la inobservancia de este problema por Pardo de Tavera.

9. Rectificamos la errata ("Bouguerao" en el texto). Se refiere a William-Adolphe Bouguereau (1825-1905), pintor francés representante del arte académico durante la segunda mitad del siglo XIX. Además del Jockey Club, una obra suya figura en la colección del Museo de Bellas Artes de Buenos Aires.

10. Es una doctrina del Derecho Internacional elaborada por el jurisconsulto argentino Carlos Calvo (1824-1906), que establece que quienes viven en un país extranjero deben establecer sus reclamaciones ante los tribunales locales, absteniéndose a ejercer presiones diplomáticas o intervenciones militares directas de su propio Estado. Varios países latinoamericanos han incluido la doctrina Calvo en sus constituciones. La Doctrina Drago es una aplicación más restrictiva y limitada de la Doctrina Calvo. 


\section{Bibliografía}

Bertoni, Lilia Ana. Patriotas, cosmopolitas y nacionalistas. Fondo de Cultura Económica, 2001.

Gaignard, Romain. La Pampa Argentina. Ocupación, población y explotación, de la conquista a la crisis mundial (1550-1930). Traducción de Ricardo Figueira. Ediciones Solar, 1989.

Gutman, Margarita. Buenos Aires 1910: Memoria del Porvenir / Buenos Aires 1910: Memories of the World to Come. Gobierno de la Ciudad de Buenos Aires, Facultad de Arquitectura y Urbanismo de la Universidad de Buenos Aires, Instituto Internacional de Medio Ambiente y Desarrollo (IIED-América Latina), 1999.

Hernández, Isabel. Los indios de Argentina. MAPFRE. Col. Indios de América, no. 4, 1992.

Maddison, Angus. La economía mundial: una perspectiva milenaria. OCDE-MundiPrensa, 2002.

Pardo De Tavera, Trinidad H. "Recuerdos de Argentina”. The Philippine Review (Revista Filipina), Manila, Feb., vol. 1, no. 2, 42-59, 1916.

Santos Cristóbal, Epifanio de los. Trinidad H. Pardo de Tavera. Imprenta Cultura Filipina, 1-49, 1913.

Sábato, Hilda (coord.). Ciudadanía politica y formación de las naciones. Perspectivas históricas de América Latina. Fondo de Cultura Económica-El Colegio de México, 1999.

Shumway, Nicolas. The Invention of Argentina. University of California Press, 1991. Viñas, David. Indios, ejército y frontera [1982]. Santiago Arcos Editor, 2013. 